\title{
A different video-assisted thoracoscopic approach for every patient or for every surgeon?
}

\author{
Mario Nosotti ${ }^{1,2}$ \& Valeria Musso*,1,2 \\ ${ }^{1}$ University of Milan, Milan, Italy \\ ${ }^{2}$ Thoracic Surgery \& Lung Transplantation Unit, Foundation IRCCS Ca' Granda Ospedale Maggiore Policlinico, Milan, Italy \\ *Author for correspondence: valeriaserena.musso@gmail.com \\ "The number of ports seems to be a secondary problem; of primary importance is the oncological \\ accuracy"
}

First draft submitted: 3 October 2018; Accepted for publication: 19 January 2019; Published online: 18 December 2019

Keywords: lobectomy • technique $\bullet$ VATS

Using a candle as a light source, the Swedish physician Hans Christian Jacobaeus was the first man who dared to explore the pleural cavity with a modified cystoscope in the early 20th century. He was animated by the desire to improve the therapeutic pneumothorax technique previously proposed by Carlo Forlanini for the treatment of tuberculosis. The thoracoscopic practice was widely used in Europe, until the advent of antituberculosis drugs decreed its sunset in the mid-1940s.

The availability of new endoscopes and solid-state video microcameras prompted the rapid and enormous success of laparoscopic cholecystectomy in the mid-80s; in the same era, thoracoscopy was brought back to the fore essentially for diagnostic purposes. In 1992, while performing the first major thoracoscopic pulmonary resection, Gianfranco Roviaro certainly did not imagine that he would place the seed for a revolution in thoracic surgery. In these early years, the video-assisted thoracoscopic (VATS) lobectomy was adopted from few visionary surgeons that set the foundation of the modern thoracoscopic surgery. Robert McKenna was among the firsts to support the individual endoscopic ligation of the hilum elements as well as the anterior position of the surgeon, instead of the posterior one as it is usually done while performing a lobectomy via posterolateral thoracotomy.

Early experiences established that VATS lobectomy led to less immediate postoperative pain than the thoracotomy approach; this important point enabled faster recovery, shorter hospital stays and prompt return to preoperative activities. Despite these early encouraging results, VATS was struggling to gain a widespread consensus. Concerns were related to the safety of hilum dissection during a close procedure, oncological adequacy, high costs and the lack of long term benefits. Such concerns were endorsed by several papers stating that VATS and open lobectomy resulted in similar impairments of pulmonary function, respiratory muscle force, 6 min walking test results and similar postoperative pain over 15 days. This discouragement brought out the fact that VATS lobectomy was not a standardized technique but that each surgeon applied his own operating strategy which in many cases did not exclude the use of costal retractors. A point on the VATS lobectomy standardized approach was established by the Cancer and Leukemia Group B 39802 by designing a prospective, multi-institutional study on technical feasibility of VATS in early non-small-cell lung cancer: the definition for VATS lobectomy included one thoracotomy $(4-8 \mathrm{~cm})$ without rib spreading, two $0.5 \mathrm{~cm}$ port incisions, conventional hilar dissection and endoscopic guidance [1]. While the standardization of VATS procedure took hold, some studies analyzed the impact of VATS lobectomy on the postoperative immunosuppression, revealing that open lobectomy had greater impairment and slower recovery [2].

\section{The proliferation of techniques}

Robert McKenna was the first to standardize the surgical procedure for VATS lobectomy from a technical perspective; in a paper published in 2006 , he reported a $2.5 \%$ conversion rate, $0.8 \%$ mortality, $0.57 \%$ local recurrence and

Future $\because$ Medicine 
a length of hospital stay of 4.78 days using his three- or four-port technique in 1100 patients [3]. Concurrently, Thomas D'Amico published his experience of 500 VATS lobectomy performed with only two incisions [4]. The perioperative (30-day) mortality was $1.2 \%$, the conversion rate was $1.6 \%$ and the median length of hospital stay was 3 days. Despite these two techniques demonstrating the feasibility and excellent results of VATS lobectomy, a Danish surgeon implemented a standardized approach to facilitate the operation; Henrik Hansen published his experience, consisting in three-port anterior approach to the hilum and 'no-touch fissure' technique, in 2011 [5]. The paper included only 156 VATS lobectomies with a conversion rate of $7.7 \%$ and a median length of stay of 5 days; even though the population was little and the results were far from being exciting, the 'Copenhagen' three-port technique was adopted in many centers. While Hansen published his multiannual experience, a young Spanish surgeon described a case of a 74-year-old female who received a lower lobe VATS lobectomy through a single-port approach [6]. Such approach, also called uniportal, was proposed by Diego Gonzales Rivas and rapidly gained the approval from several surgeons. Unexpectedly, the uniportal approach divided the thoracic surgeons' parterre; a lively debate between proponents and opponents of the approach is still ongoing.

To provide a comprehensive overview of VATS techniques, it is mandatory to mention other approaches, some of which can be described as 'peculiar'. First of all, it is fair to mention the totally endoscopic procedure proposed by the French surgeon Dominique Gossot; this elegant approach requires four to five small thoracoscopic ports and the lobe is extracted from one of those ports, properly enlarged at the end of surgery [7]. The author supported his technique advocating the steadiness of the utility thoracotomy access performed at the beginning of surgery whereas his technique leaves the surgeon free to choose its most convenient location. To be sincere, a concern about safety is reasonable if the surgeon is not of great experience and perfectly skilled.

In the 2010s, the body of clinical data showing the benefits of VATS approach for pulmonary lobectomy convinced many thoracic surgeons to undertake this procedure; thus a number of alternative procedures had been proposed as the confidence in VATS lobectomy increased. In 2011, Alaaddin Yilmaz and collaborator proposed the 'closed chest lobectomy with subxiphoid retraction' [8]; this approach included a camera port on the posterior axillary line in the sixth intercostal space followed by $\mathrm{CO}_{2}$ insufflation, two additional thoracic ports and a fourth port just under the xiphoid. The lobe was removed through the subxiphoid incision (extended); the drain was inserted through this latter incision. Joel Dunning et al. described a new technique named 'microlobectomy'; such technique included three thoracic ports plus a subxiphoid one. The ports and the instruments, including the stapler, were $5 \mathrm{~mm}$ devices; the technique was totally endoscopic with $\mathrm{CO}_{2}$ inflation [9]. In 2014, surgeons from the Koo Foundation Sun Yat-Sen Cancer Center (Taiwan) reported a subxiphoid single-incision thoracoscopic left upper lobectomy [10]. This approach required a $4 \mathrm{~cm}$ transverse incision over the subxiphoid area and the retractor to lift the sternocostal margin. The Polish surgeon Marcin Zieliński published in 2017 his experience on nine patients with lung cancer treated with an original technique named 'uniportal transcervical VATS lobectomy combined with transcervical extended mediastinal lymphadenectomy' [11]. The procedure consisted in a 6-8 cm collar incision, followed by division of anterior jugular veins bilaterally, elevation of the sternal manubrium with a hook and a transcervical extended mediastinal lymphadenectomy. The procedure then included a standard lobectomy through the cervical incision itself; one or two chest tubes were inserted through the transcervical incision. Finally, surgeons from Zhongshan Hospital of Fudan University (Shanghai, China) reported a case of 'transaxillary uniportal VATS surgery' for right upper lobectomy in 2018 [12]. The lobectomy was conducted through a single 4-cm incision in the fossa axillaris area paralleled to the skin.

\section{The evidence-based surgery}

Modern surgery should be based on the best available external clinical evidence that is considered to be randomized controlled clinical trials conducted on the volume of patients that can prove the effectiveness of a surgical procedure. Unfortunately, this high quality evidence is missing in the VATS history; nonetheless, non very recent meta-analyses performed by Chinese researchers yields interesting results. Cai et al. selected 21 retrospective and two prospective study and concluded that VATS lobectomy was associated with a longer 5-year survival (odds ratio [OR]: 1.62), higher local recurrence rate (OR: 2.15) and lower total complication rate $(\mathrm{OR}=0.45)$ compared with open surgery [13]. At the same time, Zhang et al. selected 20 papers for their meta-analysis; risk ratio (RR) was pooled revealing no significant difference in the number of total lymph nodes harvested. Distant and locoregional recurrence rates were lower in the VATS group (RR: 0.61 and RR: 0.66 respectively); finally, survival rate was significantly higher in VATS patients (RR: 1.09) [14]. These meta-analyses had a number of limitations: randomized trials were totally absent, the majority of the studies were retrospective and the heterogeneity was very high in the majority of 
the pooled analyses. More recently, Bendixen and others published a randomized study that enrolled 201 patients with stage I non-small-cell lung cancer who were scheduled for lobectomy via four-port VATS or anterolateral thoracotomy [15]. The study revealed that the proportion of patients with clinically relevant pain during the first $24 \mathrm{~h}$ after surgery was significantly lower after VATS procedure. Unfortunately, the measurement of pain using a visual scale without considering the cumulative dosage of drugs taken by the patients could be questionable. In addition, the self-reported quality of life collected with two questionnaires (EQ5D and EORTC QLQ-C30) gave contradictory results. Therefore, even if we are waiting for a large randomized trial (such as the VIOLET study, which started in 2018 in the UK), we can say that for now the evidence is in favor of VATS over open lobectomy for the treatment of lung cancer in the early stage.

Recently, Chinese researchers published a meta-analysis to compare the clinical outcomes of single-incision versus multiple-incision VATS lobectomy. The authors selected 11 trials finding that uniportal VATS had significant differences in the duration of chest tube (standardized mean difference $[S M D]=-0.42$ ), short hospital stays $(\mathrm{SMD}=-0.28)$, and pain visual analog scale in the first postoperative day (SMD $=-1.19)$ [16]. Two selected trials were randomized whereas the others were all retrospective; some of the pooled analyses had extremely high heterogeneity, namely the 5-year survival and the pain visual analog scale $\left(\mathrm{I}^{2}=96\right.$ and $89 \%$ respectively). Despite the favorable result of this meta-analysis, the debate on single or multiple incisions is still open.

\section{The surgeon \& VATS lobectomy approaches}

In 2014, Philip McElnay et al. published their experience in transitioning three consultants from open lobectomy to VATS [17]. The authors stated that formal training and adoption of the Copenhagen approach (standard threeport anterior procedure) were associated with a positive impact on VATS lobectomy rate and outcomes. A review, published a year later, found that the learning curve is not abolished by former experience in open lobectomy; residents with little experience in open surgery had similar learning curves to their more experienced colleagues [18]. In those studies, the adopted surgical techniques were multiportal; obviously a concern remains on how a surgeon with limited experience in open surgery could manage a possible catastrophic complication.

Those who are interested in learning uniportal VATS lobectomy have the possibility to attend specific courses at high volume centers. These courses' outcomes have been tested in a very recent paper and the results indicate that after the course the trainees significantly reduced their operation time, the conversion rate and the number of ports used [19].

A number of courses teaching VATS lobectomy (uni, bi or triportal) are now available worldwide, but what technique should surgical schools teach? As a director of a residency school, working in a center were multiportal and uniportal VATS approach are both regularly performed, I think that junior residents should begin with a threeor two-port approach whereas senior residents could practice uniportal approach if they feel comfortable with this technique.

Last, what technique should a staff surgeon prefer in his or her everyday practice? Considering the previously summarized scientific evidences, VATS must be preferred in case of early stage lung cancer; this choice is also endorsed by recent guidelines [20]. The number of ports seems to be a secondary problem; of primary importance is the oncological accuracy and both the multiportal and uniportal approach were properly tested and approved. Personal preference and confidence seem to be the best criteria in the decision to implement 3-2 ports approach or uniportal. Alternative approaches still require adequate scientific validation and their use should be justified only in a research program context.

\section{The patient \& VATS lobectomy approaches}

Proper explanation of the surgical procedure is an explicit responsibility of the surgeon; he or she must elucidate the therapeutic strategy to the patient, including the reasons for the specific approach chosen in his or her clinical situation.

Each particular clinical scenario could require a specific technical approach. For instance, even though it had been demonstrated that sleeve lobectomy is feasible through a single access, multiportal approaches are advisable in order to guarantee the top level of safety. Other peculiar clinical situations are large peripheral masses with negative nodes: in these cases, a subxiphoid approach could be a reasonable choice rather than a large thoracotomy. 


\section{Conclusion}

VATS lobectomy has firmly conquered the scene and it will be difficult to go back. The Copenhagen three-door or the two-door technique can be considered as techniques of choice for VATS lobectomy; these standard approaches are useful for teaching and can be practiced by the vast majority of thoracic surgeons. Uniportal access has not reached a level of scientific validation that makes it preferable over the two multiportal techniques yet; certainly, however, its practicability and effectiveness is widely demonstrated. Smart thoracic surgeons can certainly choose the uniportal technique as their standard access if they think that some advantage for the patient is actually present. Finally, surgeons must keep in mind that the fundamental point is the correct treatment of an oncological pathology and that the various techniques are only alternative ways to complete this treatment. A truly brilliant surgeon must know how to use all the techniques described above in order to adjust access to the type of illness he finds himself having to deal with in the patient's exclusive interest.

\section{Financial \& competing interests disclosure}

The authors have no relevant affiliations or financial involvement with any organization or entity with a financial interest in or financial conflict with the subject matter or materials discussed in the manuscript. This includes employment, consultancies, honoraria, stock ownership or options, expert testimony, grants or patents received or pending, or royalties.

No writing assistance was utilized in the production of this manuscript.

\section{Open access}

This work is licensed under the Attribution-NonCommercial-NoDerivatives 4.0 unported license. To view a copy of this license, visit http://creativecommons.org/licenses/by-nc-nd/4.0/

\section{References}

1. Swanson SJ, Herndon JE 2nd, D’Amico TA et al. Video-assisted thoracic surgery lobectomy: report of CALGB 39802 - a prospective, multi-institution feasibility study. J. Clin. Oncol. 25(31), 4993-4997 (2007).

2. $\mathrm{Ng} \mathrm{CS}$, Lee TW, Wan S et al. Thoracotomy is associated with significantly more profound suppression in lymphocytes and natural killer cells than video-assisted thoracic surgery following major lung resections for cancer. J. Invest. Surg. 18(2), 81-88 (2005).

3. McKenna RG Jr, Houck W, Fuller CB. Video-assisted thoracic surgery lobectomy: experience with 1100 cases. Ann. Thorac. Surg. 81(2), 421-425 (2006).

4. Onaitis MW, Petersen RP, Balderson SS et al. Thoracoscopic lobectomy is a safe and versatile procedure: experience with 500 consecutive patients. Ann. Surg. 244(3), 420-425 (2006).

5. Hansen HJ, Petersen RH, Christensen M. Video-assisted thoracoscopic surgery (VATS) lobectomy using a standardized anterior approach. Surg. Endosc. 25(4), 1263-1269 (2011).

6. Gonzalez D, Paradela M, Garcia J, Dela Torre M. Single-port video-assisted thoracoscopic lobectomy. Interact. Cardiovasc. Thorac. Surg. 12(3), 514-515 (2011).

7. Gossot D. Technical tricks to facilitate totally endoscopic major pulmonary resections. Ann. Thorac. Surg. 86(1), 323-326 (2008).

8. Yilmaz A, Van Putte BP, Van Boven WJ. Closed chest lobectomy with subxiphoid retraction. Interact. Cardiovasc. Thorac. Surg. 13(6), 549-551 (2011).

9. Dunning J, Elsaegh M, Nardini M et al. Microlobectomy: a novel form of endoscopic lobectomy. Innovations (Phila) 12(4), 247-253 (2017).

10. Liu CC, Wang BY, Shih CS, Liu YH. Subxiphoid single-incision thoracoscopic left upper lobectomy. J. Thorac. Cardiovasc. Surg. 148(6), 3250-3251 (2014).

11. Zieliński M, Rybak M, Solarczyk-Bombik K et al. Uniportal transcervical video-assisted thoracoscopic surgery (VATS) approach for pulmonary lobectomy combined with transcervical extended mediastinal lymphadenectomy (TEMLA). J. Thorac. Dis. 9(4), 878-884 (2017).

12. Shen Y, Zhang Y, Sun J, Gu J, Yuan Y, Wang Q. Transaxillary uniportal video assisted thoracoscopic surgery for right upper lobectomy. J. Thorac. Dis. 10(3), E214-E217 (2018).

13. Cai YX, Fu XN, Xu QZ, Sun W, Zhang N. Thoracoscopic lobectomy versus open lobectomy in stage I non-small cell lung cancer: a meta-analysis. PLoS ONE 8(12), e82366 (2013).

14. Zhang Z, Zhang Y, Feng $\mathrm{H}$ et al. Is video-assisted thoracic surgery lobectomy better than thoracotomy for early-stage non-small-cell lung cancer? A systematic review and meta-analysis. Eur. J. Cardiothorac. Surg. 44(3), 407-414 (2013).

15. Bendixen M, Jørgensen OD, Kronborg C et al. Postoperative pain and quality of life after lobectomy via video-assisted thoracoscopic surgery or anterolateral thoracotomy for early stage lung cancer: a randomized controlled trial. Lancet Oncol. 17(6), 836-844 (2016).

16. Zhang X, Yu Q, Lv D. The single-incision versus multiple-incision video-assisted thoracoscopic surgery in the treatment of lung cancer: a systematic review and meta-analysis. Indian J. Cancer 54(1), 291-300 (2017). 
17. McElnay P, Casali G, Batchelor T, West D. Adopting a standardized anterior approach significantly increases video-assisted thoracoscopic surgery lobectomy rates. Eur. J. Cardiothorac. Surg. 46(1), 100-105 (2014).

18. Okyere S, Attia R, Toufektzian L, Routledge T. Is the learning curve for video-assisted thoracoscopic lobectomy affected by prior experience in open lobectomy? Interact. Cardiovasc. Thorac. Surg. 21(1), 108-112 (2015).

19. Sihoe ADL, Gonzalez-Rivas D, Yang TY, Zhu Y, Jiang G. High-volume intensive training course: a new paradigm for video-assisted thoracoscopic surgery education. Interact. Cardiovasc. Thorac. Surg. 27(3), 365-371 (2018).

20. Postmus PE, Kerr KM, Oudkerk M et al. Early and locally advanced non-small-cell lung cancer (NSCLC): ESMO clinical practice guidelines for diagnosis, treatment and follow-up. Ann. Oncol. 28(Suppl. 4), iv1-iv21 (2017). 
